\title{
Continuous subcutaneous insulin infusion therapy is associated with reduced retinopathy progression compared with multiple daily injections of insulin
}

\author{
Laura J. Reid ${ }^{1,2} \cdot$ Fraser W. Gibb $^{1} \cdot$ Helen Colhoun $^{3} \cdot$ Sarah H. Wild $^{4} \cdot$ Mark W. J. Strachan $^{1} \cdot$ Karen Madill $^{5}$. \\ Baljean Dhillon ${ }^{5,6} \cdot$ Shareen Forbes ${ }^{1,2}$
}

Received: 13 October 2020 / Accepted: 1 March 2021 / Published online: 8 May 2021

(C) The Author(s) 2021

\begin{abstract}
Aims/hypothesis We aimed to compare diabetic retinopathy outcomes in people with type 1 diabetes following introduction of continuous subcutaneous insulin infusion (CSII) therapy with outcomes in people receiving continuing therapy with multiple daily insulin injections (MDI).

Methods This is a retrospective cohort study using the Scottish Care Information - Diabetes database for retinal screening outcomes and $\mathrm{HbA}_{1 \mathrm{c}}$ changes in 204 adults commenced on CSII therapy between 2013 and 2016, and 211 adults eligible for CSII during the same period but who continued on MDI therapy. Diabetic retinopathy progression (time to minimum one-grade worsening in diabetic retinopathy from baseline grading) was plotted for CSII and MDI cohorts using Kaplan-Meier curves, and outcomes were compared using multivariate Cox regression analysis adjusting for age, sex, baseline $\mathrm{HbA}_{1 \mathrm{c}}$, blood pressure, cholesterol, smoking status and socioeconomic quintile. Impact of baseline $\mathrm{HbA}_{1 \mathrm{c}}$ and change in $\mathrm{HbA}_{1 \mathrm{c}}$ on diabetic retinopathy progression was assessed within CSII and MDI cohorts.

Results CSII participants were significantly younger, were from less socially deprived areas, and had lower $\mathrm{HbA}_{1 \mathrm{c}}$ and higher diastolic $\mathrm{BP}$ at baseline. There was a larger reduction in $\mathrm{HbA}_{1 \mathrm{c}}$ at 1 year in those on CSII vs MDI $(-6 \mathrm{mmol} / \mathrm{mol}[-0.6 \%]$ vs $-2 \mathrm{mmol} / \mathrm{mol}$ $[-0.2 \%], p<0.01)$. Diabetic retinopathy progression occurred in a smaller proportion of adults following commencement of CSII vs continued MDI therapy over mean 2.3 year follow-up $(26.5 \%$ vs $18.6 \%, p=0.0097)$. High baseline $\mathrm{HbA}_{1 \mathrm{c}}(75 \mathrm{mmol} / \mathrm{mol}[9 \%])$ was associated with diabetic retinopathy progression in the MDI group $(p=0.0049)$ but not the CSII group $(p=0.93)$. Change in $\mathrm{HbA}_{1 \mathrm{c}}$ at follow-up, irrespective of baseline glycaemic status, did not significantly affect diabetic retinopathy progression in either group. Conclusions/interpretation CSII was associated with reduced diabetic retinopathy progression compared with continued MDI therapy, and may be protective against diabetic retinopathy progression for those with high baseline $\mathrm{HbA}_{1 \mathrm{c}}$. Progression of diabetic retinopathy over 3 years was not associated with a change in $\mathrm{HbA}_{1 \mathrm{c}}$.
\end{abstract}

Keywords Clinical diabetes $\cdot$ Clinical science $\cdot$ Insulin therapy $\cdot$ Microvascular complications $\cdot$ Retinopathy

Shareen Forbes

Shareen.Forbes@ed.ac.uk

1 Edinburgh Centre for Endocrinology and Diabetes, NHS Lothian, Edinburgh, UK

2 BHF Centre for Cardiovascular Science, Queen's Medical Research Institute, University of Edinburgh, Edinburgh, UK

3 Institute of Genetics and Molecular Medicine, University of Edinburgh, Edinburgh, UK

4 Usher Institute, University of Edinburgh, Edinburgh, UK

5 Princess Alexandra Eye Pavilion, NHS Lothian, Edinburgh, UK

6 Centre for Clinical Brain Sciences, School of Clinical Sciences, College of Medicine and Veterinary Medicine, University of Edinburgh, Edinburgh, UK

$\begin{array}{ll}\begin{array}{l}\text { Abbreviations } \\ \text { CGM }\end{array} & \begin{array}{l}\text { Continuous glucose monitoring } \\ \text { Continuous subcutaneous } \\ \text { CSII }\end{array} \\ \text { insulin infusion } \\ \text { GV } & \text { Glycaemic variability } \\ \text { MAGE } & \text { Mean amplitude of glucose excursions } \\ \text { MDI } & \text { Multiple daily insulin injections } \\ \text { OCT } & \text { Ocular coherence tomography } \\ \text { SCI-Diabetes } & \text { Scottish Care Information - Diabetes } \\ \text { SDRGS } & \text { Scottish Diabetic Retinopathy } \\ \text { SIMD } & \text { Grading Scheme } \\ \text { TIR } & \text { Scottish Index of Multiple Deprivation } \\ & \text { Time in range }\end{array}$




\section{Research in context}

\section{What is already known about this subject?}

- Improved glycaemic control confers long-term benefits for reduction in diabetic retinopathy risk but may be associated with early diabetic retinopathy worsening

- Introduction of continuous subcutaneous insulin infusion (CSII) therapy for management of type 1 diabetes is associated with reductions in $\mathrm{HbA}_{1 c}$ compared with multiple daily insulin injections (MDI)

- $\quad$ CSII is associated with reduced diabetic retinopathy risk vs MDI in adolescents

\section{What is the key question?}

- Is the introduction of CSII therapy associated with early diabetic retinopathy worsening or long-term benefits in diabetic retinopathy progression vs continued MDI therapy in adults with type 1 diabetes?

\section{What are the new findings?}

- No evidence was found of early diabetic retinopathy worsening following the introduction of CSII therapy in those with no or mild baseline diabetic retinopathy

- Change in $\mathrm{HbA}_{1 \mathrm{c}}$ is not associated with diabetic retinopathy progression

- There was reduced diabetic retinopathy progression in adults treated with CSII compared with MDI, particularly for those with the highest baseline $\mathrm{HbA}_{1 c}$

\section{How might this impact on clinical practice in the foreseeable future?}

- This provides reassurance that, in adults with no or mild diabetic retinopathy risk at baseline, there is no evidence of early diabetic retinopathy worsening, with diabetic retinopathy risk reduction following the introduction of CSII therapy. This will help facilitate patient-centred decision making regarding insulin treatment options and retinopathy screening intervals following treatment changes

\section{Introduction}

Diabetic retinopathy is one of the leading causes of blindness worldwide [1], and prevalence rises with age [2]. It has been well established, following the landmark DCCT, that good glycaemic control confers long-term benefits to reduce the risk of developing diabetic retinopathy [3]. However, concerns remain that rapid improvements in blood glucose level precipitate transient worsening of diabetic retinopathy [4], and many guidelines recommend controlled improvements in glycaemic targets with increased monitoring for retinopathy in the initial stages when treatment is altered [5].

In order to optimise glycaemic targets, insulin is typically delivered either via multiple daily insulin injections (MDI) or by continuous subcutaneous insulin infusion (CSII). A recent Cochrane review suggested that CSII is associated with a small but significant improvement in glycaemic control vs MDI therapy $\left(0.3 \%\right.$ absolute reduction in $\left.\mathrm{HbA}_{1 \mathrm{c}}\right)$ [6]. However, relatively few studies have evaluated whether treatment with CSII confers any benefits over MDI in reducing long-term diabetic retinopathy risk in an adult population, or whether there is any increased risk of early diabetic retinopathy worsening following a change in treatment from MDI to CSII.

Early studies assessing diabetic retinopathy progression following the introduction of CSII typically showed no improvement or deterioration of diabetic retinopathy with CSII [7, 8]. However, study numbers were small, participants were selected for CSII due to poor glycaemic control on conventional therapy and suitable comparator groups were not used. In addition, early insulin pump systems used in many previous study populations were more cumbersome as they did not have the ability to pre-programme variable basal rates and lacked safety alarms to notify users about infusion problems. A more recent study in adolescents suggests that CSII is associated with lower rates of retinopathy than MDI [9].

Our main aim in this study was to investigate retinopathy outcomes in adults with type 1 diabetes following the introduction of CSII therapy compared with those who continued on therapy with MDI using a robust clinical database system.

\section{Methods}

Study participants Participants were identified from three diabetes centres within NHS Lothian, Scotland, using the Scottish Care Information - Diabetes (SCI-Diabetes) database, which links clinical information for all registered people with diabetes in Scotland using electronic care records in primary care, hospitals and pharmacies. 
Diabetes records were reviewed for all participants with type 1 diabetes who were commenced on CSII therapy between 1 January 2013 and 1 December $2016(N=293)$. Retinal data collected during annual retinopathy screening for these participants were reviewed from 1 January 2011 to 1 December 2018. Within NHS Lothian, a 5 day structured education course on carbohydrate counting and diabetes management is recommended prior to referral for CSII therapy. To identify a control MDI group who had received a similar level of diabetes education to the CSII group, people who completed this course at a similar time to the CSII participants, but who remained on MDI therapy, were recruited for comparison $(N=277)$.

People were included if they were aged $>16$ years; had documented type 1 diabetes, defined as a clinical diagnosis of type 1 diabetes with no evidence in the historical record of $>6$ months between diagnosis and insulin requirement; and had no history of use of oral hypoglycaemic drug treatment other than adjuvant metformin. All participants were on treatment with either CSII or MDI therapy and were participating in the Scottish diabetes retinopathy screening programme during the study period. People were excluded if the date of commencing CSII therapy or completion of diabetes education could not be verified; if baseline or follow-up retinal images had not been taken, or those taken were deemed ungradable for both eyes; if they had been suspended from the retinal screening programme for assessment and potential treatment at ophthalmology clinics; or if they had the maximum severity retinopathy grading (R4) at baseline and could not therefore 'progress' to a higher diabetic retinopathy severity grade.

The study was approved by the South East Scotland Ethics Committee and NHS Lothian Caldicott Guardian, and was conducted according to the principles of the Declaration of Helsinki.

Study design This was a retrospective cohort study using routine clinical and diabetes retinal screening data. Data were extracted from SCI-Diabetes, including up-to-date information on retinal screening records, $\mathrm{HbA}_{1 \mathrm{c}}$, mode of current insulin therapy and diabetes education history, and anthropometric, metabolic and demographic data (weight, BMI, blood pressure, cholesterol, smoking history and an area-based measure of socioeconomic deprivation).

Study time Study entry (time $=0$ ) for the CSII group was the date of commencing CSII therapy. Mean lag time from completing the recommended structured diabetes education course to commencing CSII therapy was 945 days (median 841 days, IQR 333-1555 days). Study entry for the MDI group was calculated as 945 days from the date of completion of the diabetes education course to give an equivalent entry time to the CSII group using the mean lag time from education to CSII commencement. Secondary analyses calculating study entry as 841 days from the date of completion of the diabetes education course were also completed using the median lag time from education to CSII commencement, and results for these analyses can be found in the electronic supplementary material (ESM). Study exit for CSII and MDI groups was taken as the earliest occurring of any of the following: a retinal event, emigration from Scotland, death or the end of the study period on 1 December 2018.

Retinopathy assessment Diabetic retinopathy assessment was performed as part of the Scottish diabetes retinal screening programme. A single macula-centred photograph is taken for each eye every 6 to 12 months and retinopathy grading assessed using the Scottish Diabetic Retinopathy Grading Scheme (SDRGS) [10] by experienced SDRGS-qualified graders. Severity of diabetic retinopathy was classified as: 0 , no diabetic retinopathy; 1 , mild background diabetic retinopathy; 2 , moderate observable diabetic retinopathy; 3 , referable diabetic retinopathy; or 4, proliferative diabetic retinopathy [10]. Repeatability of image grading was not assessed; however, these are the same data that are used to inform clinical decision making for further retinal assessment. Images were also assigned a maculopathy grading based on whether markers of macular oedema were present. For accurate assessment for the presence of macular oedema, 3D imaging, usually using ocular coherence tomography (OCT), is required as false positives are common from 2D fundus images. As such, this study focused on retinopathy gradings rather than maculopathy gradings.

As retinopathy gradings were available for both eyes, the more severe grading was used as the baseline grading.

The diabetic retinopathy screening assessment immediately prior to the study entry date was taken as the baseline grading (median 71 [IQR 18-243] days prior to study entry date).

Retinopathy progression was defined as a minimum onegrade worsening in either eye from the baseline grading.

Assessment of glycaemic control by $\mathrm{HbA}_{1 \mathrm{c}}$ For each participant, $\mathrm{HbA}_{1 \mathrm{c}}$ data were extracted from the SCI-Diabetes database. Timings of baseline and follow-up $\mathrm{HbA}_{1 \mathrm{c}}$ values relative to the time of study entry were variable. The $\mathrm{HbA}_{1 \mathrm{c}}$ value immediately prior to the study entry date was taken as the baseline $\mathrm{HbA}_{1 \mathrm{c}}$ (median 75 [IQR 27-172] days prior to study entry date). Subsequent follow-up $\mathrm{HbA}_{1 \mathrm{c}}$ readings for each individual were identified for each subsequent 6 month period where available. Where multiple $\mathrm{HbA}_{1 \mathrm{c}}$ readings had been taken within a 6 month period, the $\mathrm{HbA}_{1 \mathrm{c}}$ value closest to, but not exceeding, the 6 month timepoint was used as the $\mathrm{HbA}_{1 \mathrm{c}}$ value for that interval. Mean study $\mathrm{HbA}_{1 \mathrm{c}}$ over 3 year 


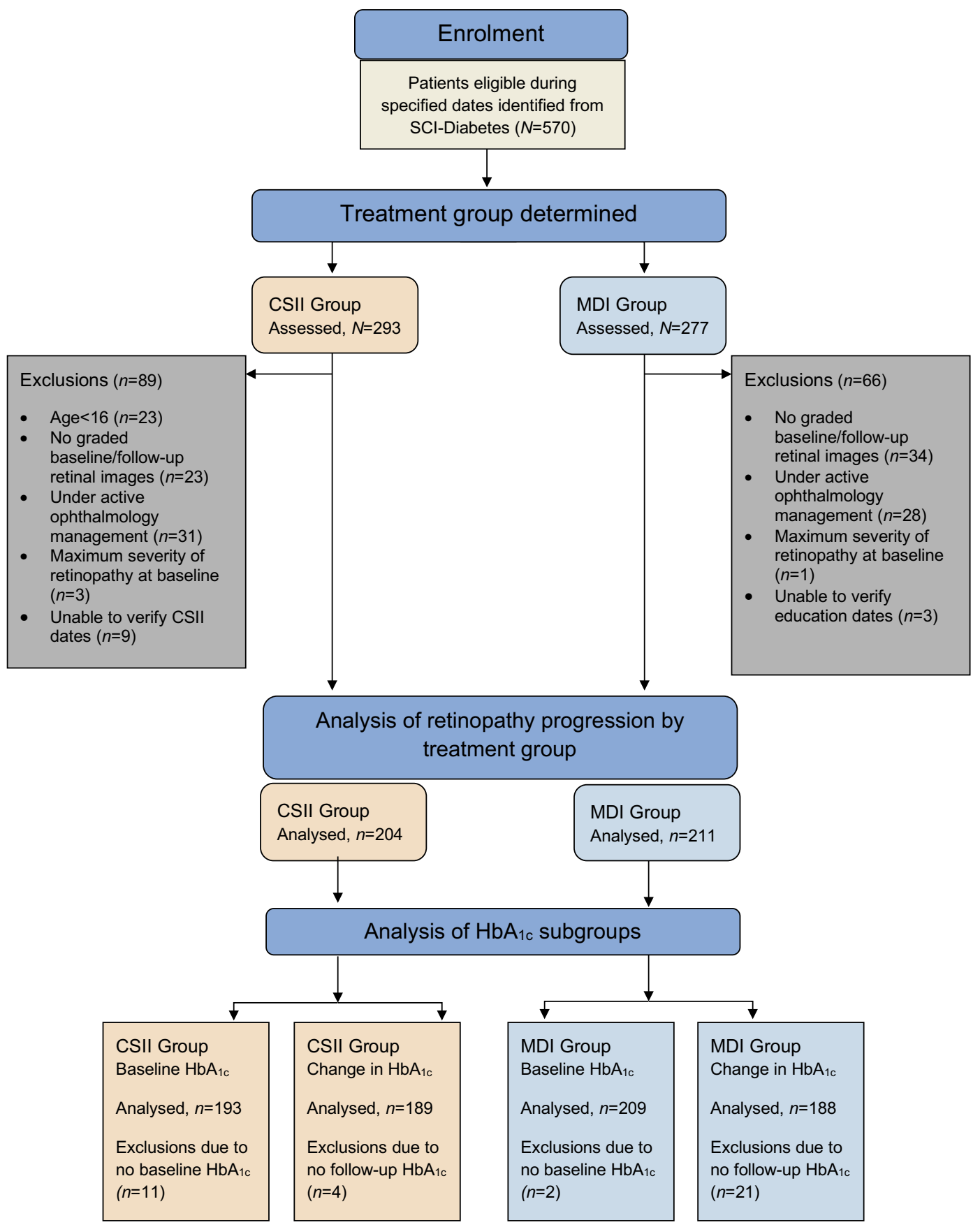

Fig. 1 Flow chart showing number of people assessed and analysed for CSII and MDI groups and exclusions

follow-up was estimated by calculating the mean $\mathrm{HbA}_{1 \mathrm{c}}$ from the 6-monthly values for each individual. The $\mathrm{HbA}_{1 \mathrm{c}}$ at approximately 1 year post study entry was also recorded, with a range of 8 to 20 months from study entry accepted as the 1 year $\mathrm{HbA}_{1 \mathrm{c}}$ value in cases where 12 month values were not available. Study exit $\mathrm{HbA}_{1 \mathrm{c}}$ was recorded as the last available $\mathrm{HbA}_{1 \mathrm{c}}$ value recorded after 20 months from study entry.

Statistical analyses Baseline variables including age, sex, diabetes duration, baseline $\mathrm{HbA}_{1 \mathrm{c}}$, socioeconomic status (assessed using quintile of Scottish Index of Multiple
Deprivation [SIMD] score [11]) and diastolic BP were summarised as median with IQR for continuous data and as percentage for categorical data. In the CSII vs MDI groups, baseline demographic and metabolic data were compared using the unpaired $t$ test for continuous normally distributed data and $\chi^{2}$ test or Fisher's exact test for categorical data. Kaplan-Meier plots were used to assess time to an event corresponding to retinopathy progression or exit from the study for another reason (death, emigration, end of study period) in CSII and MDI groups, with calculation of statistical differences between groups using the logrank test. Groups 
Table 1 Baseline demographics and metabolic characteristics

\begin{tabular}{|c|c|c|c|}
\hline Characteristic & $\begin{array}{l}\text { CSII } \\
(n=204)\end{array}$ & $\begin{array}{l}\text { MDI } \\
(n=211)\end{array}$ & $p$ value \\
\hline Age at diagnosis (years) & $15(10-26)$ & $21(12-33)$ & $<0.001$ \\
\hline Age at study entry (years) & $38(29-48)$ & $43(31-53)$ & $<0.001$ \\
\hline Diabetes duration (years) & $18(11-25)$ & $16(8-27)$ & 0.63 \\
\hline Sex M:F (\%M) & $76: 128(37.3)$ & $90: 121(42.7)$ & 0.31 \\
\hline Weight $(\mathrm{kg})$ & $78.9(67.6-90.3)$ & $79.5(67.6-91.5)$ & 0.84 \\
\hline BMI $\left(\mathrm{kg} / \mathrm{m}^{2}\right)$ & $26.9(24.0-31.2)$ & $27.1(24.2-30.4)$ & 0.97 \\
\hline $\mathrm{HbA}_{1 \mathrm{c}}(\mathrm{mmol} / \mathrm{mol})$ & $66(58-74)$ & $67(60-80)$ & $<0.05$ \\
\hline $\mathrm{HbA}_{1 \mathrm{c}}(\%)$ & $8.2(7.5-8.9)$ & $8.3(7.6-9.5)$ & $<0.05$ \\
\hline SIMD & $4(3-5)$ & $3(2-5)$ & $<0.05$ \\
\hline Cholesterol (mmol/l) & $4.7(4.2-5.2)$ & $4.8(4.2-5.4)$ & 0.14 \\
\hline Creatinine $(\mu \mathrm{mol} / \mathrm{l})$ & $73(67-83)$ & $74(68-84)$ & 0.26 \\
\hline Systolic BP (mm/Hg) & $128(118-140)$ & $128(120-138)$ & 0.95 \\
\hline Diastolic BP (mm/Hg) & $78(73-84)$ & $77(71-83)$ & $<0.001$ \\
\hline Smoking status & & & 0.20 \\
\hline Non-smoker & $141(69)$ & $131(62)$ & \\
\hline Ex-smoker & $48(24)$ & $55(26)$ & \\
\hline Current smoker & $15(7)$ & $25(12)$ & \\
\hline Baseline diabetic retinopathy grading & & & 0.10 \\
\hline R0 & $93(45.6)$ & $100(47.4)$ & \\
\hline $\mathrm{R} 1$ & $109(53.4)$ & $101(47.9)$ & \\
\hline $\mathrm{R} 2$ & 0 & $2(0.9)$ & \\
\hline $\mathrm{R} 3$ & $2(1.0)$ & $8(3.8)$ & \\
\hline R4 & Excluded & Excluded & \\
\hline
\end{tabular}

Data are median (IQR) or number (\%) unless otherwise indicated. $p$ values were calculated using unpaired $t$ test for continuous numerical data and $\chi^{2}$ test or Fisher's exact test for categorical data. Baseline grading indicates the overall baseline retinopathy grading for each individual. As retinal data were available for both eyes, the more severe retinal grading outcome for that individual was used as the baseline

F, female; M, male were not matched, but characteristics were similar between the groups and potential confounders were included as covariates in Cox proportional hazard analyses. Univariate and multivariate Cox proportional hazards analyses were performed using the following covariates: CSII or MDI treatment group, age, sex, diabetes duration, baseline $\mathrm{HbA}_{1 \mathrm{c}}$, systolic $\mathrm{BP}$, diastolic $\mathrm{BP}$, cholesterol, creatinine, SIMD, smoking status and baseline diabetic retinopathy grading.

To assess the impact of baseline, mean study, 1 year and study exit $\mathrm{HbA}_{1 \mathrm{c}}$, participants were stratified using $\mathrm{HbA}_{1 \mathrm{c}}$ values $(<58 \mathrm{mmol} / \mathrm{mol}[<7.5 \%]), 58-75 \mathrm{mmol} / \mathrm{mol}[7.5-$ $9 \%$ ] and $>75 \mathrm{mmol} / \mathrm{mol}[>9 \%]$ ) and compared using Kaplan-Meier plots as above. Similarly, to assess the impact of the change in $\mathrm{HbA}_{1 \mathrm{c}}$ at 1 year, participants were stratified using change in $\mathrm{HbA}_{1 \mathrm{c}}$ value ( $>-5 \mathrm{mmol}$ [>-0.5\%], -5 to $5 \mathrm{mmol} / \mathrm{mol}[-0.5$ to $0.5 \%$ ] and $>5 \mathrm{mmol} / \mathrm{mol}$ [ $>0.5 \%$ ] change) and compared using Kaplan-Meier plots as above.

Statistical significance was assumed for $p<0.05$. Statistical analyses were completed using R version 3.4.1 (https://www. R-project.org/.)

\section{Results}

Study populations Between 1 January 2013 and 1 December 2016, 293 people with type 1 diabetes who commenced CSII therapy were identified. Of these, 89 were excluded: 23 were aged $<16$ years at commencement of CSII, 23 had no available baseline and/or follow-up graded retinal screening results, 31 had been excluded from screening for further ophthalmology assessment or treatment, three had the maximum severity retinopathy grading at baseline and for a further nine we were not able to verify if the dates for commencing CSII were correct. The remaining 204 were included in the analysis (Fig. 1).

We identified 277 MDI control participants who had completed structured diabetes education at a similar time to the CSII cohort but who did not proceed to CSII therapy, largely due to patient preference. Of these, 66 were excluded: 34 had no available baseline and/or follow-up graded retinal screening results, 28 had been excluded from screening for further ophthalmology assessment or treatment, one had the maximum severity grading at baseline and for a further three 
Table 2 Stratified $\mathrm{HbA}_{1 \mathrm{c}}$ analysis in CSII and MDI groups

\begin{tabular}{llll}
\hline Variable & $\begin{array}{l}\text { CSII } \\
(n=204)\end{array}$ & $\begin{array}{l}\text { MDI } \\
(n=211)\end{array}$ & $p$ value \\
\hline Baseline $\mathrm{HbA}_{1 \mathrm{c}}(/$ total $n$ with data $)$ & $/ 193$ & $/ 209$ & 0.06 \\
$<58 \mathrm{mmol} / \mathrm{mol}(<7.5 \%), n(\%)$ & $42(21.8)$ & $44(21.1)$ & \\
$58-75 \mathrm{mmol} / \mathrm{mol}(7.5-9 \%), n(\%)$ & $107(55.4)$ & $96(45.9)$ & \\
$>75 \mathrm{mmol} / \mathrm{mol}(>9 \%), n(\%)$ & $44(22.8)$ & $69(33)$ & $<0.001$ \\
Change in $\mathrm{HbA}$ ac at 1 year $(/$ total $n$ with data) & $/ 189$ & $/ 188$ & \\
$>-5 \mathrm{mmol} / \mathrm{mol}(>-0.5 \%), n(\%)$ & $98(51.9)$ & $55(29.3)$ & 0.03 \\
-5 to $5 \mathrm{mmol} / \mathrm{mol}(-0.5$ to $0.5 \%), n(\%)$ & $70(37.0)$ & $99(52.7)$ & \\
$>5 \mathrm{mmol} / \mathrm{mol}(>0.5 \%), n(\%)$ & $21(11.1)$ & $34(18.1)$ & \\
Change in HbA at study exit $(/$ total $n$ with data) & $/ 142$ & $36(29.0)$ & \\
$>-5 \mathrm{mmol} / \mathrm{mol}(>-0.5 \%), n(\%)$ & $63(44.4)$ & $61(49.2)$ & \\
-5 to $5 \mathrm{mmol} / \mathrm{mol}(-0.5$ to $0.5 \%), n(\%)$ & $58(40.8)$ & $21(21.8)$ & \\
$>5 \mathrm{mmol} / \mathrm{mol}(>0.5 \%), n(\%)$ & $21(14.8)$ &
\end{tabular}

Table showing numbers of all participants stratified to subgroups for baseline $\mathrm{HbA}_{1 \mathrm{c}}$ and change in $\mathrm{HbA}_{1 \mathrm{c}}$ at 1 year and study exit. $p$ values comparing subgroups for all CSII and MDI or matched CSII and MDI cohorts were calculated using $\chi^{2}$ test we were not able to verify if the dates for diabetes education were correct. The remaining 211 were included in the analysis (Fig. 1).

Baseline demographic and metabolic data are shown in Table 1. CSII participants were significantly younger, with earlier age of diabetes diagnosis, lower baseline $\mathrm{HbA}_{1 \mathrm{c}}$, higher diastolic BP and with lower proportions of people in more deprived socioeconomic quintiles. The majority of participants had either no diabetic retinopathy or mild diabetic retinopathy at baseline. There were no significant differences in baseline diabetic retinopathy gradings between CSII vs MDI cohorts.

$\mathrm{HbA}_{1 \mathrm{c}}$ changes in CSII and MDI The median number of 6monthly $\mathrm{HbA}_{1 \mathrm{c}}$ values per person collected over a 3 year study interval was 5 (IQR 4-6). There was a small but statistically significant difference in baseline $\mathrm{HbA}_{1 \mathrm{c}}$ (CSII $66 \mathrm{mmol} / \mathrm{mol}$ [8.2\%] vs MDI $67 \mathrm{mmol} / \mathrm{mol}$ [8.3\%], $p<0.01)$. In the CSII group, there were significant reductions in mean study $\mathrm{HbA}_{1 \mathrm{c}}(62 \mathrm{mmol} / \mathrm{mol}[7.8 \%]), 1$ year $\mathrm{HbA}_{1 \mathrm{c}}$ (59 $\mathrm{mmol} / \mathrm{mol}[7.5 \%])$ and study exit $\mathrm{HbA}_{1 \mathrm{c}}(61 \mathrm{mmol} / \mathrm{mol}$ [7.7\%]) from baseline (all $p<0.001$ ). In contrast, there were no significant changes in mean study $\mathrm{HbA}_{1 \mathrm{c}}, 1$ year $\mathrm{HbA}_{1 \mathrm{c}}$ or study exit $\mathrm{HbA}_{1 \mathrm{c}}$ (all $67 \mathrm{mmol} / \mathrm{mol}$ [8.3\%]) from baseline in the MDI group. At all follow-up timepoints, CSII participants had a significantly lower $\mathrm{HbA}_{1 \mathrm{c}}$ than MDI participants $(p<0.001)$, and a greater $\mathrm{HbA}_{1 \mathrm{c}}$ reduction (1 year: $-6 \mathrm{mmol} / \mathrm{mol}[-0.6 \%] \mathrm{vs}-1 \mathrm{mmol} / \mathrm{mol}[-0.1 \%], p<0.01$; study exit: $-4 \mathrm{mmol} / \mathrm{mol}[-0.4 \%]$ vs $-2 \mathrm{mmol} / \mathrm{mol}[-0.2 \%]$, $p=0.12$ ). In both groups, univariate regression analysis showed higher baseline $\mathrm{HbA}_{1 \mathrm{c}}$ was significantly associated with greater reductions in $\mathrm{HbA}_{1 \mathrm{c}}$ at 1 year $(p<0.0001)$.
The distribution of $\mathrm{HbA}_{1 \mathrm{c}}$ in the CSII and MDI groups is shown in Table 2. There was a higher proportion of MDI vs CSII participants in the highest baseline $\mathrm{HbA}_{1 \mathrm{c}}$ group (>75 mmol/mol [>9\%]) but differences were not statistically significant (Table 2). Follow-up $\mathrm{HbA}_{1 \mathrm{c}}$ in CSII and MDI groups at 1 year increased by $5 \mathrm{mmol} / \mathrm{mol}(0.5 \%)$ in $11.1 \%$ vs $18.1 \%$ and decreased by more than $5 \mathrm{mmol} / \mathrm{mol}(0.5 \%)$ in $51.9 \%$ vs $29.3 \%(p<0.001$; Table 2$)$. Changes at study exit showed a similar pattern between MDI and CSII groups, though numbers of participants with available data for analysis were lower $(p=0.03$; Table 2$)$.

Fig. 2 Retinopathy in comparator treatment groups (a) and $\mathrm{HbA}_{1 \mathrm{c}}$ subgroups (b-e). Kaplan-Meier survival plots compare event-free survival rates in CSII/MDI treatment groups (a) and $\mathrm{HbA}_{1 \mathrm{c}}$ subgroups (b-e). An event corresponds to diabetic retinopathy progression and was defined as a minimum one-grade worsening in either eye from the baseline grading. Vertical dashes indicate participants who were censored due to incomplete 3 year follow-up. (a) Comparison of CSII (blue) and MDI (red) participants for the entire cohort. CSII was associated with significantly reduced retinopathy progression over 3 years compared with MDI $(p=0.0097)$. (b, c) Comparison of participants with baseline $\mathrm{HbA}_{1 \mathrm{c}}<58 \mathrm{mmol} / \mathrm{mol}(7.5 \%)$ (low: lilac), $58-75 \mathrm{mmol} / \mathrm{mol}(7.5-9 \%)$ (middle: blue) or $>75 \mathrm{mmol} / \mathrm{mol}(9 \%)$ (high: red) in the CSII group (b) and the MDI group (c). High baseline $\mathrm{HbA}_{1 \mathrm{c}}(>75 \mathrm{mmol} / \mathrm{mol}[9 \%])$ was associated with increased diabetic retinopathy progression in the MDI group $(p=0.0049)$ but was not a determinant of diabetic retinopathy progression in the CSII group $(p=0.93)$. (d, e) Comparison of unmatched participants with change in $\mathrm{HbA}_{1 \mathrm{c}}$ at 1 year of less than $-5 \mathrm{mmol} / \mathrm{mol}(0.5 \%)$ (decrease: lilac), -5 to 5 $\mathrm{mmol} / \mathrm{mol}(0.5$ to $0.5 \%)$ (stable: blue) or more than $5 \mathrm{mmol} / \mathrm{mol}(0.5 \%)$ (increase: red) in the CSII group (d) and the MDI group (e). Change in $\mathrm{HbA}_{1 \mathrm{c}}$ at follow-up did not significantly impact diabetic retinopathy progression in either cohort 

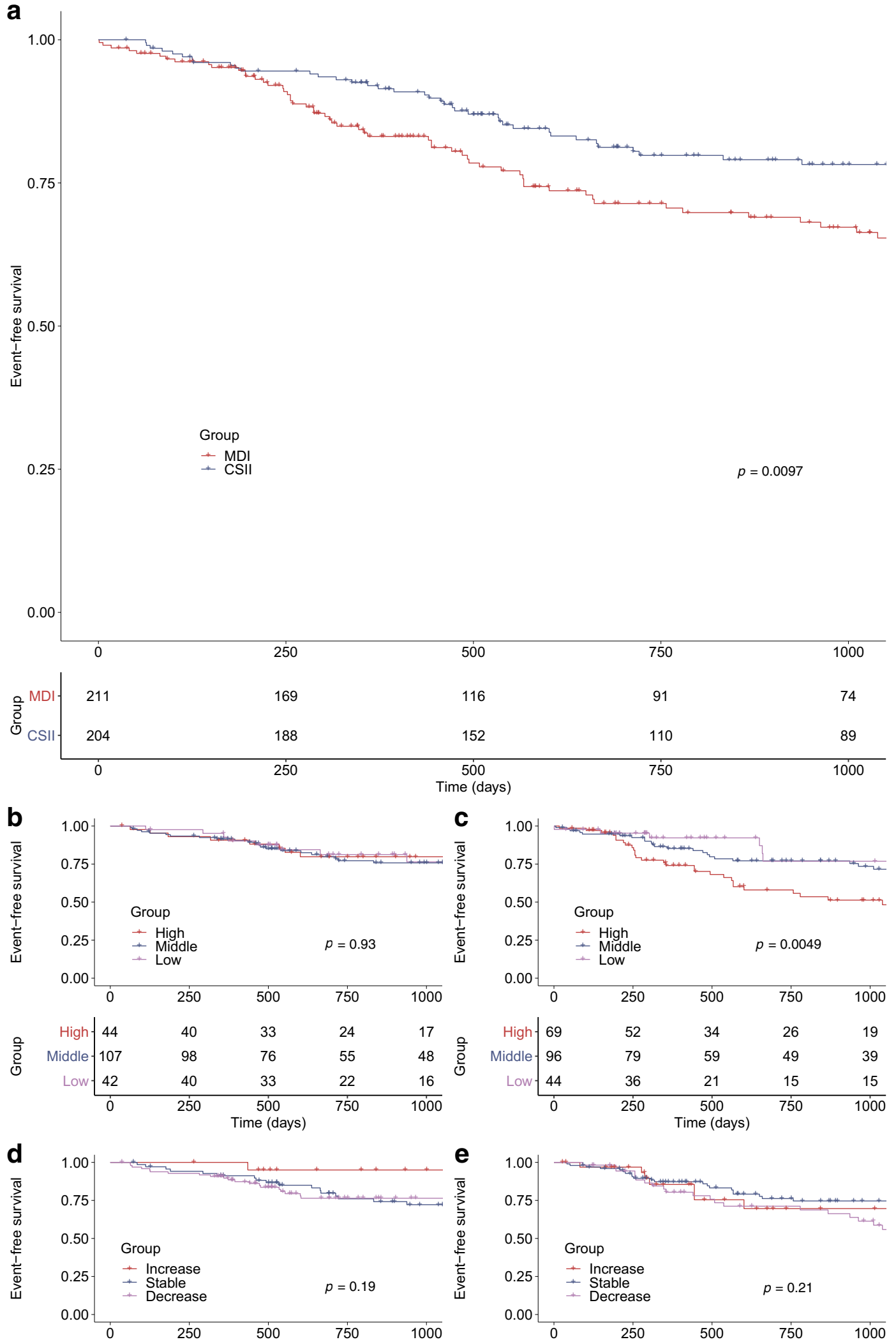

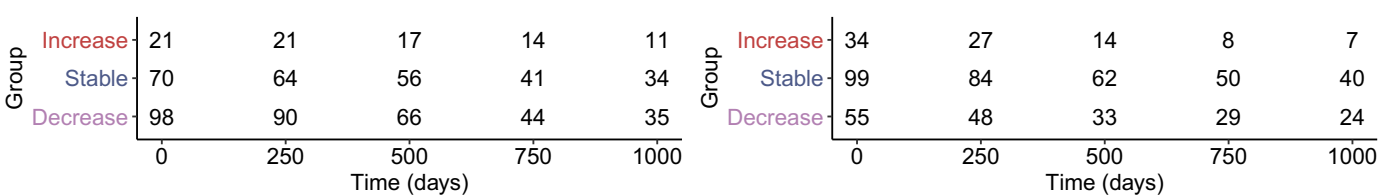


Table 3 Hazard ratios for covariates on univariate and multivariate Cox proportional hazards analysis

\begin{tabular}{|c|c|c|c|c|c|c|}
\hline \multirow[t]{2}{*}{ Covariate } & \multicolumn{3}{|c|}{ Univariate analysis } & \multicolumn{3}{|c|}{ Multivariate analysis } \\
\hline & HR & $(95 \% \mathrm{CI})$ & $p$ value & HR & $(95 \% \mathrm{CI})$ & $p$ value \\
\hline Pump group & 0.58 & $0.39,0.88$ & 0.01 & 0.56 & $0.34,0.91$ & 0.02 \\
\hline Age at study entry & 0.98 & $0.96,0.99$ & 0.99 & 0.97 & $0.96,0.99$ & $<0.01$ \\
\hline Male sex & 0.84 & $0.55,1.29$ & 0.43 & 0.69 & $0.40,1.19$ & 0.18 \\
\hline Diabetes duration & 1.00 & $0.98,1.01$ & 0.65 & 1.03 & $1.02,1.05$ & $<0.001$ \\
\hline Baseline $\mathrm{HbA}_{1 \mathrm{c}}$ & 1.03 & $1.01,1.03$ & $<0.001$ & 1.03 & $1.01,1.04$ & $<0.001$ \\
\hline Systolic & 1.00 & $0.98,1.01$ & 0.68 & 1.00 & $0.98,1.02$ & 0.92 \\
\hline Diastolic & 0.99 & $0.97,1.02$ & 0.61 & 1.01 & $0.99,1.04$ & 0.36 \\
\hline Cholesterol & 0.97 & $0.78,1.22$ & 0.82 & 0.94 & $0.73,1.21$ & 0.62 \\
\hline Creatinine & 1.00 & $0.99,1.01$ & 0.87 & 1.01 & $1.00,1.02$ & 0.01 \\
\hline SIMD & 0.89 & $0.77,1.03$ & 0.13 & 0.94 & $0.79,1.12$ & 0.51 \\
\hline \multicolumn{7}{|l|}{ Smoking status } \\
\hline Non-smoker & 1.00 (Ref.) & & & 1.00 (Ref.) & & \\
\hline Ex-smoker & 1.54 & $0.98,2.41$ & 0.06 & 1.89 & $1.13,3.17$ & 0.02 \\
\hline Current smoker & 1.60 & $0.84,3.08$ & 0.15 & 0.94 & $0.43,2.07$ & 0.88 \\
\hline \multicolumn{7}{|c|}{ Baseline diabetic retinopathy grading } \\
\hline R0 & 1.00 (Ref.) & & & 1.00 (Ref.) & & \\
\hline $\mathrm{R} 1$ & 0.11 & $0.06,0.20$ & $<0.001$ & 0.07 & $0.03,0.13$ & $<0.001$ \\
\hline $\mathrm{R} 2$ & 5.43 & $1.32,22.32$ & 0.02 & 2.90 & $0.62,13.6$ & 0.18 \\
\hline $\mathrm{R} 3$ & 1.04 & $0.38,2.84$ & 0.94 & 0.28 & $0.09,0.86$ & 0.03 \\
\hline
\end{tabular}

Ref., reference

Retinopathy events in CSII vs MDI Kaplan-Meier curves describing time to a diabetic retinopathy progression event for comparator groups are shown in Fig. 2a-e. Mean followup for the entire cohort was 839 days ( 2.3 years), with diabetic retinopathy progression occurring in 38 participants (18.6\%) in the CSII group vs 56 participants (26.5\%) in the MDI group (Fig. 2a; $p=0.0097$ ). Of these, unilateral retinal progression was identified in $21 / 56(37.5 \%)$ people in the MDI group vs $14 / 38$ (36.8\%) people in the CSII group, while the rest had bilateral retinal progression.

Pump participants had a reduced risk of diabetic retinopathy progression on univariate (HR $0.58, p=0.01$ ) and multivariate (HR $0.56, p=0.02$ ) Cox proportional hazards analysis, adjusting for age, sex, diabetes duration, baseline $\mathrm{HbA}_{1 \mathrm{c}}, \mathrm{BP}$, cholesterol, creatinine, SIMD, smoking status and baseline diabetic retinopathy grading (Table 3 ).

Those with mild retinopathy at baseline were also at low risk of progression (HR 0.07), with the majority of events occurring in those with no baseline retinopathy (76/94, $80.9 \%$ ). Older age was also associated with reduced risk of diabetic retinopathy progression (HR 0.97), though longer diabetes duration (HR 1.03), increased creatinine (HR 1.01) and history of previous smoking (HR 1.89) were associated with increased diabetic retinopathy progression risk on multivariate analysis.

Higher baseline $\mathrm{HbA}_{1 \mathrm{c}}$ was associated with increased diabetic retinopathy progression risk for the entire cohort on univariate and multivariate analyses (HR 1.03, $p<0.001$; Table 3). However, this effect was driven by the MDI cohort, with baseline $\mathrm{HbA}_{1 \mathrm{c}}$ having no significant impact on the frequency of diabetic retinopathy progression occurring in the CSII cohort (Fig. 2b; $p=0.93$ ), while in the MDI cohort $\mathrm{HbA}_{1 \mathrm{c}}>75 \mathrm{mmol} / \mathrm{mol}(>9 \%)$ was associated with a significantly higher proportion of participants with diabetic retinopathy progression (28/69 participants, $40.6 \%)$ than those with $\mathrm{HbA}_{1 \mathrm{c}}<58 \mathrm{mmol} / \mathrm{mol}(<7.5 \%)(6 / 44$ participants, $13.6 \%)$ (Fig. $2 \mathrm{c} ; p=0.0049$ ). The same outcomes were found when groups were stratified by mean study $\mathrm{HbA}_{1 \mathrm{c}}$, with no significant impact of high mean study $\mathrm{HbA}_{1 \mathrm{c}}$ on diabetic retinopathy progression noted in the CSII cohort $(p=0.26)$, while high mean study $\mathrm{HbA}_{1 \mathrm{c}}$ was associated with increased diabetic retinopathy progression in the MDI cohort $(p=0.023)$. $\mathrm{HbA}_{1 \mathrm{c}}$ values at 1 year and study exit showed no significant impact on the frequency of diabetic retinopathy progression in either cohort. Change in $\mathrm{HbA}_{1 \mathrm{c}}$ at 1 year from baseline was not associated with diabetic retinopathy progression in either cohort (CSII: Fig. 2d [ $p=0.19]$, MDI: Fig. 2e [ $p=0.21]$ ).

\section{Discussion}

In this real-world study, using a robust clinical database and a nationalised single diabetic retinopathy scoring system, we observed that CSII therapy was associated with significantly 
lower diabetic retinopathy progression over a 3 year follow-up period in adults with type 1 diabetes who had completed structured diabetes education than in those on MDI therapy who had completed an equivalent structured diabetes education programme (18.6\% in CSII vs $26.5 \%$ in MDI, $p=0.0097$ ). In addition, there was no evidence of early diabetic retinopathy worsening in those using CSII compared with MDI over the first 18 months. This is despite significantly larger reductions in $\mathrm{HbA}_{1 \mathrm{c}}$ in the CSII group $(6 \mathrm{mmol} / \mathrm{mol}[0.5 \%]$ reduction) vs the MDI group (1 mmol/mol [0.1\%] reduction) at 1 year post study entry $(p<0.001)$. Findings were confirmed on multivariate analysis adjusting for multiple potential confounders.

Those with longer duration of diabetes were found to be at higher risk of diabetic retinopathy progression, which was expected as this is a well-established risk factor for diabetic retinopathy [1]. Surprisingly, older age was associated with a small but significant reduction in risk of diabetic retinopathy progression in our cohort. This was driven by MDI participants, with no significant effect of age on diabetic retinopathy progression when CSII participants were analysed in isolation. The addition of drug therapies such as statins and antihypertensives in older participants may have contributed to diabetic retinopathy risk reduction; however, we were unable to assess this in our cohort.

Studies of diabetic retinopathy progression in adults are lacking in real-world settings. However, our findings are consistent with a longitudinal study of adolescents (aged 1220 years) treated with either CSII or MDI therapy over a period of 15 years [9]. The study showed a significantly lower risk of developing retinopathy in those treated with CSII vs MDI (OR $0.66)$, though the majority of assessments (79\%) were from participants who were only reviewed once during the study period. Proportions of people developing retinopathy were slightly lower than in our cohort (17\% in CSII, 22\% in MDI); however, this is likely to be consistent with a patient cohort of younger age and shorter diabetes duration than in our study. A further study assessed retinal changes in 31 adults following initiation of CSII using a range of imaging modalities, including OCT, and showed stable retinal characteristics over 1 year with no evidence of early diabetic retinopathy worsening [12].

High baseline $\mathrm{HbA}_{1 \mathrm{c}}(75 \mathrm{mmol} / \mathrm{mol}$ [ $\left.>9 \%]\right)$ was associated with increased diabetic retinopathy progression in the MDI group. In contrast, diabetic retinopathy progression in the CSII group was not found to be associated with baseline $\mathrm{HbA}_{1 \mathrm{c}}$. In the MDI group there were no significant reductions in follow-up $\mathrm{HbA}_{1 \mathrm{c}}$ values when compared with baseline levels. However, in the CSII group, follow-up $\mathrm{HbA}_{1 \mathrm{c}}$ values were significantly reduced from baseline, and were lower than $\mathrm{HbA}_{1 \mathrm{c}}$ levels assessed at the same timepoints in the MDI group. Absolute change in $\mathrm{HbA}_{1 \mathrm{c}}$ at 1 year from baseline was not significantly associated with diabetic retinopathy progression for either group.
We hypothesise that factors intrinsic to CSII therapy are protective against diabetic retinopathy progression in those with high baseline $\mathrm{HbA}_{1 \mathrm{c}}$, while those with high baseline $\mathrm{HbA}_{1 \mathrm{c}}$ on MDI remain at increased diabetic retinopathy risk. Many of the MDI participants did not achieve a substantial reduction in $\mathrm{HbA}_{1 \mathrm{c}}$ on follow-up and therefore had continued exposure to high glycaemic levels which may have contributed to increased diabetic retinopathy risk. This is supported by the fact that high mean study $\mathrm{HbA}_{1 \mathrm{c}}$ was significantly associated with diabetic retinopathy progression in the MDI group, though this was not true in the CSII group.

While exposure to high glycaemic levels is a wellestablished risk factor for diabetic retinopathy, recurrent disabling hypoglycaemia may also increase diabetic retinopathy risk [13]. Though recurrent disabling hypoglycaemia is a possible indication for consideration of CSII therapy, it was not possible for this to be accurately assessed within our cohorts and levels of hypoglycaemia within the groups may have differed. It is therefore possible that some of those perceived to have good glycaemic control, reflected by a lower baseline $\mathrm{HbA}_{1 \mathrm{c}}$, were exposed to higher levels of hypoglycaemia prior to the study period, which could have contributed to increased diabetic retinopathy risk. CSII therapy has been shown to reduce frequency of hypoglycaemia [14], which may also have conferred a benefit in terms of diabetic retinopathy risk, even in those with no $\mathrm{HbA}_{1 \mathrm{c}}$ reduction.

Other factors related to better control of diabetes (including glycaemic variability [GV], discussed further below) may also have contributed to the reduction in diabetic retinopathy observed in the CSII group.

It is important to note that, within our retinopathy screening programme in Scotland, when people are commenced on CSII therapy, recommendations are in place with regard to modifications to early $\mathrm{HbA}_{1 \mathrm{c}}$ targets where appropriate, particularly for those with high baseline $\mathrm{HbA}_{1 \mathrm{c}}$ levels, and improved surveillance for retinopathy [5]. As such, the reductions in $\mathrm{HbA}_{1 \mathrm{c}}$, although significant in our study, may have been achieved more gradually in the CSII group, and may have facilitated improved retinopathy outcomes.

Glycaemic control as measured by $\mathrm{HbA}_{1 \mathrm{c}}$ has been shown to be important in reducing diabetic retinopathy progression, as evidenced from the DCCT study [15]. However, other studies do not demonstrate an association between baseline $\mathrm{HbA}_{1 \mathrm{c}}$, or change in $\mathrm{HbA}_{1 \mathrm{c}}$, and diabetic retinopathy progression following initiation of CSII therapy [16]. Evidence from the DCCT also showed that $\mathrm{HbA}_{1 \mathrm{c}}$ changes did not fully explain the risk of diabetic retinopathy progression in type 1 diabetes, and that other features of glucose control, such as the extent of postprandial glucose excursions or counterregulatory responses to hypoglycaemia, which are not easily reflected by a summary measure such as $\mathrm{HbA}_{1 \mathrm{c}}$, may have an impact on the risk of developing complications [15]. DCCT analyses 
assessing time in range (TIR) from seven-point fingerstick data showed this had a strong association with the development of microvascular complications including retinopathy [17], though earlier DCCT analyses suggest that within-day GV and mean amplitude of glucose excursions (MAGE) were not predictive of diabetic retinopathy [18].

More widespread availability of continuous glucose monitoring (CGM) in recent years has led to expanding interest in the role of glycaemic markers other than $\mathrm{HbA}_{1 \mathrm{c}}$, including TIR, GV and MAGE, with recommendations now in place for their use in routine diabetes management [19].

There is growing evidence from CGM that these markers are associated with diabetic retinopathy in type 2 diabetes [20-22]; however, less is known about their role in type 1 diabetes [23]. We and others have reported that islet transplantation in recipients with type 1 diabetes is associated with diminished $\mathrm{GV}$ and reductions in $\mathrm{HbA}_{1 \mathrm{c}}$ in association with diminished progression of diabetic retinopathy $[24,25$, unpublished data (Reid L, Lam A, Dhillon B, Duncan K, Ibbotson C, Sutherland A, Casey J, Koh A, Rudinsky C, Tennant M, Malcolm A, Shapiro AMJ, Senior P, Forbes S (2019)]. Further studies assessing the impact of GV on diabetic retinopathy progression are needed.

CSII is associated with higher initial costs due to the expense of the pump, necessary consumables and pump education [26]. However, longer-term cost-benefit analyses studies indicate that such costs are offset by improved glycaemic control, enhanced quality-of-life markers and reductions in diabetes complications, and demonstrate that CSII is in fact a cost-effective treatment in type 1 diabetes $[26,27]$. Many cost-benefit models highlight the reduced morbidity- and mortality-related costs secondary to reductions in problematic hypoglycaemia associated with CSII therapy [26], and projected cost savings related to diminished microand macrovascular complications are also evident, with an $18.3 \%$ lifetime reduction in severe visual loss with CSII vs MDI therapy [27].

The strengths of this study are that it is a relatively large study providing real-world data on diabetic retinopathy progression in type 1 diabetes in an adult cohort following initiation of CSII therapy. Furthermore, diabetic retinopathy assessment was performed within a single retinopathy screening programme. It provides reassurance that, in people with no diabetic retinopathy or mild diabetic retinopathy at baseline, there is no evidence of increased risk of diabetic retinopathy progression following initiation of CSII, and there is longterm benefit particularly in those with the highest $\mathrm{HbA}_{1 \mathrm{c}}$ compared with continued MDI therapy.

The study has several limitations. As a retrospective realworld study, timings of retinal imaging and $\mathrm{HbA}_{1 \mathrm{c}}$ collection were not uniform for participants over the study period. In addition, participants were not randomised to receive either CSII or MDI therapy, resulting in potential confounding and allocation bias. Indeed, at baseline the CSII group was significantly younger with earlier age of diabetes onset, lower baseline $\mathrm{HbA}_{1 \mathrm{c}}$ and lower diastolic $\mathrm{BP}$, and lived in less socioeconomically deprived areas than the MDI group. Multivariate analyses were performed to minimise the impact of these differences. Study entry time for the MDI group, who did not have any specific intervention, was based on the lag time from receiving structured education to commencing CSII therapy. Although there was some variability in this lag time, when data were reassessed using an alternative study entry time based on the median lag time (841 days) rather than mean lag time (945 days) (see ESM Methods), outcomes were unchanged, with results still showing significantly fewer retinal events in the CSII group vs the MDI group (see ESM Results and ESM Fig. 1). Retinal data were sourced from the diabetes retinopathy screening programme, and therefore people who had no retinal screening results could not be assessed (7.8\% CSII, 12.3\% MDI). This could represent a population of non-attenders who are not fully engaging with aspects of their diabetes management, and as such may be at higher risk of developing diabetic retinopathy. In addition, few participants with advanced retinal disease, who are known to be at the highest level of risk of diabetic retinopathy [28], were assessed as these people leave the screening programme to enter into a management pathway under the care of ophthalmologists, though numbers excluded due to receiving ophthalmology care were similar in both groups $(10.6 \%$ CSII, $10.1 \% \mathrm{MDI})$. Reporting of retinopathy outcomes using SDRGS assessment is not the gold standard, and therefore we may have missed more subtle retinal changes that could have been picked up by using Early Treatment Diabetic Retinopathy Study (ETDRS) screening; however, as SDRGS is designed to detect clinically significant changes we feel findings are still clinically relevant. These problems relating to the use of screening data will have affected both groups, and therefore their impact on the study analysis was felt to be relatively small. Glycaemic analysis was limited to $\mathrm{HbA}_{1 \mathrm{c}}$ data. Though this remains the gold standard for glycaemic assessment, further studies using CGM will help fully characterise the range of glycaemic factors involved in diabetic retinopathy progression. Finally, this study was conducted in a predominantly white population across three diabetes centres from a single Scottish region, where a national diabetic retinopathy screening service is offered for all people affected by diabetes. Therefore, results may not be generalisable to all people with type 1 diabetes from other ethnic groups, or where access to diabetic retinopathy screening is limited.

Conclusion This observational study has demonstrated reduced diabetic retinopathy progression in a real-world population with type 1 diabetes commenced on CSII vs those who continued on MDI, with no evidence of early diabetic 
retinopathy worsening. Although reductions in $\mathrm{HbA}_{1 \mathrm{c}}$ were seen due to CSII therapy, these were not associated with a reduction in diabetic retinopathy progression and as such other glycaemic factors associated with CSII therapy may play a role. Further prospective studies using CGM may help establish if reductions in glycaemic excursions are causal in reducing the progression of diabetic retinopathy and other microvascular diabetes complications.

Supplementary Information The online version contains peer-reviewed but unedited supplementary material available at https://doi.org/10.1007/ s00125-021-05456-w.

Acknowledgements Some of the data were presented as an abstract at the Diabetes UK Professional Conference in 2019. The authors wish to thank the Royal College of Surgeons (Royal Blind); Edinburgh and Lothians Health Foundation; the Scottish Diabetes Research Network; the BHF Centre for Cardiovascular Science; the Royal Infirmary Edinburgh, Edinburgh, UK; Western General Hospital, Edinburgh, UK; and St John's Hospital, Livingston, UK.

Data availability The datasets generated during and/or analysed during the current study are available from the corresponding author on reasonable request.

Funding This research received grant funding from the Royal College of Surgeons (Royal Blind) and Edinburgh and Lothians Health Foundation.

Authors' relationships and activities The authors declare that there are no relationships or activities that might bias, or be perceived to bias, their work.

Contribution statement LJR, FWG, HC, SHW, BD and SF contributed to study design. LJR, FWG, MWJS, KM, SHW and SF facilitated acquisition of data. LJR collected and analysed data. LJR and SF wrote the manuscript. All authors reviewed and edited the manuscript and have approved the final version of the manuscript to be published. SF is the study guarantor.

Open Access This article is licensed under a Creative Commons Attribution 4.0 International License, which permits use, sharing, adaptation, distribution and reproduction in any medium or format, as long as you give appropriate credit to the original author(s) and the source, provide a link to the Creative Commons licence, and indicate if changes were made. The images or other third party material in this article are included in the article's Creative Commons licence, unless indicated otherwise in a credit line to the material. If material is not included in the article's Creative Commons licence and your intended use is not permitted by statutory regulation or exceeds the permitted use, you will need to obtain permission directly from the copyright holder. To view a copy of this licence, visit http://creativecommons.org/licenses/by/4.0/.

\section{References}

1. Yau JW, Rogers SL, Kawasaki R et al (2012) Global prevalence and major risk factors of diabetic retinopathy. Diabetes Care 35(3): 556-564. https://doi.org/10.2337/dc11-1909

2. Leasher JL, Bourne RR, Flaxman SR et al (2016) Global Estimates on the Number of People Blind or Visually Impaired by Diabetic
Retinopathy: A Meta-analysis From 1990 to 2010. Diabetes Care 39(9):1643-1649. https://doi.org/10.2337/dc15-2171

3. Nathan DM (2014) The Diabetes Control and Complications Trial/ Epidemiology of Diabetes Interventions and Complications Study at 30 Years: Overview. Diabetes Care 37:9-16

4. Feldman-Billard S, Larger E, Massin P (2018) Early worsening of diabetic retinopathy after rapid improvement of blood glucose control in patients with diabetes. Diabetes Metab 44(1):4-14. https://doi.org/10.1016/j.diabet.2017.10.014

5. Diabetic Retinopathy Guidelines Expert Working Party (2012) The Royal College of Ophthalmologists Diabetic Retinopathy Guidelines December 2012. Available from https://www.rcophth. ac.uk/wp-content/uploads/2014/12/2013-SCI-301-FINAL-DRGUIDELINES-DEC-2012-updated-July-2013.pdf. Accessed 10 Jun 2020

6. Misso ML, Egberts KJ, Page M, O'Connor D, Shaw J (2010) Continuous subcutaneous insulin infusion (CSII) versus multiple insulin injections for type 1 diabetes mellitus. Cochrane Database Syst Rev Art. no.: CD005103. https://doi.org/10.1002/14651858. CD005103.pub2

7. van Ballegooie E, Hooymans JM, Timmerman Z et al (1984) Rapid deterioration of diabetic retinopathy during treatment with continuous subcutaneous insulin infusion. Diabetes Care 7(3):236-242. https://doi.org/10.2337/diacare.7.3.236

8. Kelly TM, Sanborn GE, Haug PJ, Edwards CQ (1984) Effect of insulin infusion pump use on diabetic retinopathy. Arch Ophthalmol 102(8):1156-1159. https://doi.org/10.1001/archopht. 1984.01040030934017

9. Zabeen B, Craig ME, Virk SA et al (2016) Insulin Pump Therapy Is Associated with Lower Rates of Retinopathy and Peripheral Nerve Abnormality. PLoS One 11(4):e0153033. https://doi.org/10.1371/ journal.pone. 0153033

10. Scottish Diabetic Retinopathy Screening Collaborative (2007) Scottish Diabetic Retinopathy Grading Scheme 2007 v1.1. Available from https:/www.ndrs.scot.nhs.uk/wp-content/uploads/ 2013/04/Grading-Scheme-2007-v1.1.pdf. Accessed 10 Jun 2020

11. Scottish Government (2016) Scottish Index of Multiple Deprivation. Available from https://www2.gov.scot/Topics/ Statistics/SIMD/. Accessed 1 Dec 2020

12. Klefter ON, Hommel E, Munch IC, Norgaard K, Madsbad S, Larsen M (2016) Retinal characteristics during 1 year of insulin pump therapy in type 1 diabetes: a prospective, controlled, observational study. Acta Ophthalmol 94(6):540-547. https://doi.org/10. 1111/aos.13066

13. Wright RJ, Frier BM (2008) Vascular disease and diabetes: is hypoglycaemia an aggravating factor? Diabetes Metab Res Rev 24(5):353-363. https://doi.org/10.1002/dmrr.865

14. Quiros C, Gimenez M, Rios P et al (2016) Long-term outcome of insulin pump therapy: reduction of hypoglycaemia and impact on glycaemic control. Diabet Med 33(10):1422-1426. https://doi.org/ 10.1111/dme.13094

15. The Diabetes Control and Complications Trial Research Group (1995) The Relationship of Glycemic Exposure (HbA1c) to the Risk of Development and Progression of Retinopathy in the Diabetes Control and Complications Trial. Diabetes 44(8):968983. https://doi.org/10.2337/diab.44.8.968

16. Marchand L, Kawasaki-Ogita Y, Place J et al (2017) Long-Term Effects of Continuous Subcutaneous Insulin Infusion on Glucose Control and Microvascular Complications in Patients With Type 1 Diabetes. J Diabetes Sci Technol 11(5):924-929. https://doi.org/10. 1177/1932296817700161

17. Beck RW, Bergenstal RM, Riddlesworth TD et al (2019) Validation of Time in Range as an Outcome Measure for Diabetes Clinical Trials. Diabetes Care 42(3):400-405. https:// doi.org/10.2337/dc18-1444 
18. Kilpatrick ES, Rigby AS, Atkin SL (2009) Effect of Glucose Variability on the Long-Term Risk of Microvascular Complications in Type 1 Diabetes. Diabetes Care 32:1901-1903. https://doi.org/10.2337/dc09-0109

19. Battelino T, Danne T, Bergenstal RM et al (2019) Clinical Targets for Continuous Glucose Monitoring Data Interpretation: Recommendations From the International Consensus on Time in Range. Diabetes Care 42(8):1593-1603. https://doi.org/10.2337/ dci19-0028

20. Lu J, Ma X, Zhou J et al (2018) Association of Time in Range, as Assessed by Continuous Glucose Monitoring, With Diabetic Retinopathy in Type 2 Diabetes. Diabetes Care 41(11):2370 2376. https://doi.org/10.2337/dc18-1131

21. Nalysnyk L, Hernandez-Medina M, Krishnarajah G (2010) Glycaemic variability and complications in patients with diabetes mellitus: evidence from a systematic review of the literature. Diabetes Obes Metab 12(4):288-298. https://doi.org/10.1111/j. 1463-1326.2009.01160.x

22. Hsu CR, Chen YT, Sheu WH (2015) Glycemic variability and diabetes retinopathy: a missing link. J Diabetes Complicat 29(2): 302-306. https://doi.org/10.1016/j.jdiacomp.2014.11.013

23. Sartore G, Chilelli NC, Burlina S, Lapolla A (2013) Association between glucose variability as assessed by continuous glucose monitoring (CGM) and diabetic retinopathy in type 1 and type 2 diabetes. Acta Diabetol 50(3):437-442. https://doi.org/10.1007/ s00592-013-0459-9
24. Thompson DM, Meloche M, Ao Z et al (2011) Reduced progression of diabetic microvascular complications with islet cell transplantation compared with intensive medical therapy. Transplantation 91(3):373-378. https://doi.org/10.1097/TP. 0b013e31820437f3

25. Forbes S, Senior PA, Shapiro AMJ (2018) Islet transplantation in type 1 diabetes: moving forward. Lancet Diabetes Endocrinol 6(7): 516-517. https://doi.org/10.1016/s2213-8587(18)30107-4

26. Roze S, Smith-Palmer J, Valentine W, de Portu S, Norgaard K, Pickup JC (2015) Cost-effectiveness of continuous subcutaneous insulin infusion versus multiple daily injections of insulin in Type 1 diabetes: a systematic review. Diabet Med 32(11):1415-1424. https://doi.org/10.1111/dme.12792

27. Roze S, Valentine WJ, Zakrzewska KE, Palmer AJ (2005) Healtheconomic comparison of continuous subcutaneous insulin infusion with multiple daily injection for the treatment of Type 1 diabetes in the UK. Diabet Med 22(9):1239-1245. https://doi.org/10.1111/j. 1464-5491.2005.01576.x

28. Ochs A, McGurnaghan S, Black MW et al (2019) Use of personalised risk-based screening schedules to optimise workload and sojourn time in screening programmes for diabetic retinopathy: A retrospective cohort study. PLoS Med 16(10):e1002945. https:// doi.org/10.1371/journal.pmed.1002945

Publisher's note Springer Nature remains neutral with regard to jurisdictional claims in published maps and institutional affiliations. 